\title{
Screening for iron overload: Lessons from the HEmochromatosis and IRon Overload Screening (HEIRS) Study
}

\begin{abstract}
Paul C Adams MD¹, James C Barton MD², Gordon D McLaren MD³, Ronald T Acton PhD4, Mark Speechley PhD5 , Christine E McLaren $\mathrm{PhD}^{6}$, David M Reboussin $\mathrm{PhD}^{7}$, Catherine Leiendecker-Foster MS ${ }^{8}$, Emily L Harris PhD MPH${ }^{9}$, Beverly M Snively PhD ${ }^{7}$, Thomas Vogt MD ${ }^{10}$, Phyliss Sholinsky MSPH ${ }^{11}$, Elizabeth Thomson DNSc RN CCG ${ }^{12}$, Fitzroy W Dawkins $M D^{13}$, Victor R Gordeuk $M D^{10}$, John H Eckfeldt MD PhD
\end{abstract}

PC Adams, JC Barton, GD McLaren, et al. Screening for iron overload: Lessons from the HEmochromatosis and IRon Overload Screening (HEIRS) Study. Can J Gastroenterol 2009;23(11):769-772.

BACKGROUND: The HEmochromatosis and IRon Overload Screening (HEIRS) Study provided data on a racially, ethnically and geographically diverse cohort of participants in North America screened from primary care populations.

METHODS: A total of 101,168 participants were screened by testing for HFE C282Y and H63D mutations, and measuring serum ferritin concentration and transferrin saturation. In the present review, lessons from the HEIRS Study are highlighted in the context of the principles of screening for a medical disease as previously outlined by the World Health Organization.

RESULTS: Genetic testing is well accepted, with minimal risk of discrimination. Transferrin saturation has high biological variability and relatively low sensitivity to detect HFE C282Y homozygotes, which limits its role as a screening test. Symptoms attributable to HFE C282Y homozygosity are no more common in individuals identified by population screening than in control subjects.

CONCLUSIONS: Generalized population screening in a primary care population as performed in the HEIRS Study is not recommended. There may be a role for focused screening in Caucasian men, with some debate regarding genotyping followed by phenotyping, or phenotyping followed by genotyping.

Key Words: Haemochromatosis; Hemochromatosis; HFE; Iron overload

The present review summarizes the findings of the HEmochromatosis and IRon Overload Screening (HEIRS) Study (1) (Table 1). The HEIRS Study was designed to evaluate the prevalence, genetic and environmental determinants, and potential clinical, personal and societal effects of iron overload and hemochromatosis in a multicentre, multiethnic sample of 101,168 primary care adults 25 years of age or older. The subheadings are based on the guidelines for screening for a medical illness established by the World Health Organization (2).

\section{Le dépistage de la surcharge en fer : Des leçons tirées de l'étude HEIRS sur l'hémochromatose et le dépistage de la surcharge en fer}

HISTORIQUE : L'étude HEIRS sur l'hémochromatose et le dépistage de la surcharge en fer fournit des données sur une cohorte de participants de races, d'ethnies et de lieux géographiques diversifiés en Amérique du Nord, dépistés au sein de populations de soins primaires.

MÉTHODOLOGIE : Au total, 101168 participants ont subi un dépistage des mutations de HFE C282Y et H63D et ont fait mesurer leur concentration de ferritine sérique et leur saturation de transferrine. Dans la présente analyse, les auteurs font ressortir les leçons tirées de l'étude HEIRS dans le contexte des principes de dépistage d'un état médical déjà décrit par l'Organisation mondiale de la santé.

RÉSULTATS : Le dépistage génétique est bien accepté et s'associe à un risque de discrimination minimal. La saturation de transferrine comporte une variabilité biologique élevée et une sensibilité relativement faible pour déceler les homozygotes HFE C282Y, ce qui en limite le rôle à titre de test de dépistage. Les symptômes attribuables à l'homozygotie HFE C282Y ne sont pas plus courants chez les personnes sélectionnées par dépistage au sein de la population que chez les sujets témoins.

CONCLUSIONS : Le dépistage au sein d'une population générale de soins primaires, tel qu'il a été effectué dans l'étude HEIRS, n'est pas recommandé. Le dépistage ciblé pourrait être utile chez les hommes de race blanche, mais on ne s'entend pas sur l'intérêt de précéder la détermination du génotype par celle du phénotype ou vice-versa.

The condition should be considered an important health problem

Hemochromatosis is considered by many physicians to be a rare disease, although with a genetic prevalence of one in 227 , it is one of the most common genetic diseases among Northern European populations (1). The case definition of hemochromatosis has been framed in different ways depending on the demonstration of iron overload, a typical genetic test (HFE C282Y homozygosity) or a combination of clinical and biochemical tests (3). The disease has been under-represented on

${ }^{1}$ Department of Medicine, London Health Sciences Centre, London, Ontario; ${ }^{2}$ Southern Iron Disorders Center, Birmingham, Alabama; ${ }^{3}$ VA Long Beach Healthcare System, Long Beach, and Univeristy of California, Irvine, California; ${ }^{4}$ Department of Microbiology, University of Alabama, Birmingham, Alabama, USA; ${ }^{5}$ University of Western Ontario, London, Ontario; ${ }^{6}$ Department of Epidemiology, University of California, Irvine, California; ${ }^{7}$ Division of Public Health Sciences, Wake Forest University School of Medicine, Winston-Salem, North Carolina; ${ }^{8}$ Departments of Laboratory Medicine and Pathology, University of Minnesota, Minneapolis, Minnesota; ${ }^{9}$ Translational Genomics Research Branch, National Institute of Dental and Craniofacial Research, National Institutes of Health, Department of Health and Human Services, Bethesda, Maryland; ${ }^{10}$ Kaiser Permanente Center for Health Research, Honolulu, Hawaii; ${ }^{11}$ Department of Epidemiology and Biostatistics, Epidemiology Branch, National Heart, Lung, and Blood Institute; ${ }^{12}$ National Human Genome Research Institute, National Institutes of Health, Department of Health and Human Services, Bethesda, Maryland; ${ }^{13}$ Department of Medicine, Howard University, Washington DC, USA

Correspondence: Dr Paul C Adams, Department of Medicine, University Hospital, 339 Windermere Road, London, Ontario

N6A 5A5. Telephone 519-685-8500 ext 35375, fax 519-663-3549, e-mail padams@uwo.ca

Received for publication June 23, 2009. Accepted June 25, 2009 


\section{TABLE 1}

\section{Lessons from the HEmochromatosis and IRon Overload Screening (HEIRS) Study}

- Generalized population screening in a primary care population as performed in the HEIRS Study is not recommended

- Genetic testing is well accepted, with minimal risk of discrimination (13)

- An elevated serum ferritin is very common, particularly in Asians, Pacific Islanders and African Americans, and may not be an indication for phlebotomy. In the absence of HFE C282Y homozygosity, this finding usually does not represent an increase of iron stores of $>4 \mathrm{~g}$ (11)

- Transferrin saturation has high biological variability and relatively low sensitivity to detect HFE C282Y homozygotes, which limits its role as a screening test (9)

- Most symptoms typically attributed to HFE C282Y homozygosity are no more common in individuals identified by population screening than in control subjects lacking HFE mutations (6)

- Mild increases in body iron stores in the range of $2 \mathrm{~g}$ to $3 \mathrm{~g}$ are common in non-HFE C282Y homozygotes, but iron overload, defined as iron stores $>4 \mathrm{~g}$, is most common in Caucasian men who are HFE C282Y homozygotes (22)

- There may be a role for focused screening in Caucasian men with some debate about whether to perform genotyping followed by phenotyping or, phenotyping followed by genotyping (23)

hospital discharge and death data, and is an uncommon indication for liver transplantation. Treatment of the major medical complications of hemochromatosis, such as cirrhosis of the liver and hepatocellular carcinoma, are costly but these occur in a small fraction of HFE C282Y homozygotes. Populationbased studies estimate that approximately $5 \%$ of male HFE C282Y homozygotes may have cirrhosis (4,5), and hepatocellular carcinoma may occur in 10\% of cirrhotic patients. Most patients identified in population-based hemochromatosis screening studies are asymptomatic (6).

\section{There should be a treatment for the condition}

Iron depletion by phlebotomy is a well-recognized treatment for iron overload associated with hemochromatosis. Recent studies have demonstrated a reversal of hepatic fibrosis by phlebotomy, which is the strongest evidence to support this therapy (7). There have been no randomized trials to evaluate the benefits of phlebotomy therapy and most experts believe that such a trial would be unethical.

Facilities for diagnosis and treatment should be available The diagnosis of hemochromatosis can be made with iron tests such as serum transferrin saturation and ferritin, and a genetic test for the C282Y mutation in the HFE gene. These tests are widely available. Liver biopsy is no longer required as a diagnostic test in an HFE C282Y homozygote. Many jurisdictions allow healthy hemochromatosis patients to become voluntary blood donors.

\section{There should be a latent stage of the disease}

Biochemical abnormalities in transferrin saturation may precede clinical signs and symptoms by 40 to 50 years. Genetic testing has the potential to identify individuals who are at increased risk of developing iron overload. It can be difficult to predict which $\mathrm{C} 282 \mathrm{Y}$ homozygotes develop progressive iron overload with liver damage (8).
There should be a test or examination for the condition Homozygosity of the C282Y mutation in the HFE gene is found in more than $90 \%$ of hemochromatosis patients. Transferrin saturation and serum ferritin are not ideal measures for diagnostic screening. Transferrin saturation has considerable biological variability and in the HEIRS study, had a sensitivity of $75 \%$, with a specificity of $95 \%$ and positive predictive value of $3.5 \%$ for detecting HFE C282Y homozygotes. A fasting sample did not provide any advantages over a random sample (9). Serum ferritin increases with iron overload but also increases with inflammation, fatty liver and alcohol consumption (10). In the HEIRS Study, a large number of Asian, Pacific Islander and African American participants were demonstrated to have elevated serum ferritin, without apparent iron overload $(11,12)$.

\section{The test should be acceptable to the population}

Serum transferrin saturation and ferritin testing are widely acceptable to the population. They are also widely used for detection of iron deficiency. These iron measures are routinely requested by physicians who evaluate patients for fatigue, liver abnormalities, anemia and other conditions. Such testing occasionally leads to a diagnosis of hemochromatosis or iron overload. The acceptability of genetic testing for hemochromatosis was less well established at the time of the HEIRS Study. A major innovation of the HEIRS Study was the clear demonstration that genetic testing was highly acceptable to participants from diverse ethnic groups. After one year of follow-up in the study, there was no evidence of genetic discrimination (13). Most participants were satisfied to be notified of their genetic test results by mail $(14,15)$.

\section{The natural history of the disease should be adequately} understood

During the HEIRS Study, several large, long-term epidemiological studies with stored DNA reported clinical outcomes in relation to genetic testing for HFE gene mutations. This allowed for a glimpse of the natural history of untreated disease in HFE hemochromatosis. It is apparent in all of these studies that a progressive rise in serum ferritin is not inevitable in hemochromatosis, and many HFE C282Y homozygotes appear to have a plateau in serum ferritin or a decrease in ferritin over time $(8,16,17)$. These observations have strongly diminished the enthusiasm for population screening for hemochromatosis because there is little evidence of differences in clinical outcome between screened and unscreened groups to justify the intervention of the screening. This does not imply that there are no patients with severe complications of iron overload. These patients were being referred and treated by many of the HEIRS investigators at the same time as asymptomatic C282Y homozygotes were being identified in their communities through the HEIRS screening. Emerging information suggests that many of these milder cases may not develop symptoms or complications of iron overload, regardless of whether they are treated with phlebotomy.

There should be an agreed policy on who to treat

Because it is unclear which individuals with hemochromatosis will develop complications of iron overload, it has been a standard practice to offer iron depletion by phlebotomy to all patients with an elevated serum ferritin (greater than $200 \mu \mathrm{g} / \mathrm{L}$ 
in women, greater than $300 \mu \mathrm{g} / \mathrm{L}$ in men). However, in light of the epidemiological studies, the prognosis of participants with mild iron overload may be excellent without any iron-depleting treatment. Less is known about non-HFE or nonclassical hemochromatosis. Therefore, there are uncertainties regarding the need and rationale for treating all patients and, thus, the justification for widespread screening is unconvincing.

\section{The total cost of finding a case should be economically} balanced in relation to medical expenditure as a whole The HEIRS Study was not designed to analyze screening and medical follow-up costs and charges. Cost-effectiveness studies should reveal an incremental benefit in the screened group compared with the unscreened group to justify any costs associated with screening and follow-up (including follow-up of incidental findings, other illness and iron deficiency). These concepts have been explored in previous studies that have used HEIRS Study data regarding the prevalence of cirrhosis $(18-20)$. The conclusions of these studies have been mostly supportive of screening but have not been widely accepted by public health and policy groups.

\section{Case-finding should be a continuous process, not just a 'once and for all' project}

It seems unlikely that screening for hemochromatosis would ever be endorsed for all North Americans and performed in a centralized way as in the HEIRS Study, regardless of ethnicity. The highest risk group identified in the HEIRS Study was Caucasian men. To focus on this group for systematic hemochromatosis testing would improve screening efficiency but accessing this subpopulation remains challenging because men tend not to have regular interactions with primary care providers. Testing at the time of periodic assessments of cholesterol, prostate-specific antigen or blood pressure has some merit but would likely only capture a small percentage of cases. It is more likely that the diagnosis would be made incidentally in most cases. Once a patient is discovered, a family history and pedigree investigation is an important aspect of management in detecting at risk individuals who may benefit from additional evaluation (21). Increasing physician and patient awareness may be the best strategy to improve the rate of early diagnosis and treatment of hemochromatosis.

FUNDING: The HEIRS Study was initiated and funded by the National Heart, Lung, and Blood Institute, in conjunction with the National Human Genome Research Institute (Bethesda, Maryland). The study is supported by contracts N01-HC05185 (University of Minnesota, Minneapolis, Minnesota); N01-HC05186, N01-CM07003-74, and Minority CCOP (Howard University, Washington DC); N01-HC05188 (University of Alabama, Birmingham, Alabama); N01-C05189 (Kaiser Permanente Center for Health Research); N01-HC05190 (University of California, Irvine, California); N01-HC05191 (London Health Sciences Centre, London, Ontario); and N01-C05192 (Wake Forest University, Winston-Salem, North Carolina). Additional support was provided by the University of Alabama at Birmingham General Clinical Research Center (GCRC) grant M01-RR00032, Howard University GCRC grant M01-RR10284, and the University of California, Irvine UCSD/UCI Satellite GCRC grant M01-RR00827, sponsored by the National Center for Research Resources, National Institutes of Health (Bethesda, Maryland); Howard University Research Scientist Award UH1-HL03679-05 from the National Heart, Lung, and Blood Institute, and the Office of Research on Minority Health (VRG); and Southern Iron Disorders Center (Birmingham, Alabama) (JCB, RTA).

ACKNOWLEDGEMENTS: The authors acknowledge the assistance of all the HEIRS Study investigators and its participants in making this study possible.

DISCLAIMER: The views expressed in the present article do not represent those of the National Institutes of Health, the National Heart, Lung, and Blood Institute, the National Human Genome Research Institute, the National Institute for Dental and Craniofacial Research, or the Department of Health and Human Services.

DISCLOSURE: The authors of this manuscript have no conflicts of interest to disclose.

\section{REFERENCES}

1. Adams PC, Reboussin DM, Barton JC, et al. Hemochromatosis and iron-overload screening in a racially diverse population. $\mathrm{N}$ Engl J Med 2005;352:1769-78.

2. Wilson JM, Junger G. The principles and practice of screening for disease. Public Health Papers WHO 1968;34:26-39.

3. Adams PC. Hemochromatosis case definition - out of focus ? Nat Clin Gastroenterol Hepatol 2006;3:178-9.

4. Asberg A, Hveem K, Thorstensen K, et al. Screening for hemochromatosis - high prevalence and low morbidity in an unselected population of 65,238 persons. Scand J Gastroenterol 2001;36:1108-15.

5. Powell LW, Dixon JL, Ramm GA, et al. Screening for hemochromatosis in asymptomatic subjects with or without a family history. Arch Int Med 2006;166:294-301.

6. McLaren GD, McLaren CE, Adams PC, et al. Clinical manifestations of hemochromatosis in HFE homozygotes identified by screening. Can J Gastroenterol 2008;22:923-30.

7. Falize L, Guillygomarch A, Perrin M, et al. Reversibility of hepatic fibrosis in treated genetic hemochromatosis: A study of 36 cases. Hepatology 2006;44:472-7.

8. Gurrin LC, Osborne NJ, Constantine CC, et al. The natural history of serum iron indices for HFE C282Y homozygosity associated with hereditary hemochromatosis. Gastroenterology 2008;135:1945-52.

9. Adams PC, Reboussin DM, Press RD, et al. Biological variability of transferrin saturation and unsaturated iron binding capacity. Am J Med 2007;120:999:e1-e7.

10. Waalen J, Felitti VJ, Gelbart T, Beutler E. Screening for hemochromatosis by measuring ferritin levels: A more effective approach. Blood 2008;111:3373-6.

11. Harris EL, McLaren CE, Reboussin DM, et al. Serum ferritin and transferrin saturation in Asians and Pacific Islanders. Arch Intern Med 2007;167:722-6.

12. Dawkins FW, Gordeuk VR, Snively BM, et al. African Americans at risk for increased iron stores or liver disease. Am J Med 2007;120:734-9.

13. Hall MA, Barton JC, Adams PC, et al. Genetic screening for iron overload: No evidence of discrimination at one year. J Fam Practice 2007;56:829-33.

14. Anderson R, Press N, Tucker D, et al. Patient acceptability of genotypic testing for hemochromatosis in primary care. Genet Med 2005;7:557-63.

15. Harrison HF, Harrison BW, Walker AP, et al. Screening for hemochromatosis and iron overload: Satisfaction with results notification and understanding of mailed results in unaffected participants of the HEIRS Study. Genet Test 2008;12:491-500.

16. Pankow JS, Boerwinkle E, Adams PC, et al. HFE C282Y homozygotes have reduced low-density lipoprotein cholesterol: 
The Atherosclerosis Risk in Communities (ARIC) Study. Transl Res 2008;152:3-10.

17. Andersen RV, Tybjaerg-Hansen A, Appleyard M, Birgens H, Nordestgaard BG. Hemochromatosis mutations in the general population: Iron overload progression rate. Blood 2004;103:2914-9.

18. Gagne G, Reinharz D, Laflamme N, Adams PC, Rousseau F. Hereditary hemochromatosis: Effect of mutation penetrance and prevalence on cost-effectiveness of screening modalities. Clin Genet 2007;71:46-58.

19. Rogowski W. The cost-effectiveness of screening for hereditary hemochromatosis in Germany: A remodeling study. Med Decis Making 2009;29:224-38.
20. Adams PC, Valberg LS. Screening blood donors for hereditary hemochromatosis: Decision analysis model comparing genotyping to phenotyping. Am J Gastroenterol 1999;94:1593-600.

21. Acton RT, Barton JC, Passmore LV, et al. Accuracy of family history of hemochromatosis or iron overload: The hemochromatosis and iron overload screening study. Clin Gastroenterol Hepatol 2008;6:934-8.

22. Gordeuk VR, Reboussin DM, McLaren CE, et al. Serum ferritin concentrations and body iron stores in a multicenter, multiethnic primary-care population. Am J Hematol 2008;83:618-26.

23. Phatak PD, Bonkovsky HL, Kowdley KV. Hereditary hemochromatosis: Time for targeted screening. Ann Int Med 2008;149:270-2. 


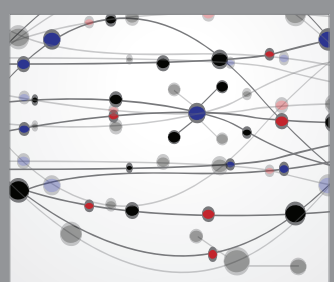

The Scientific World Journal
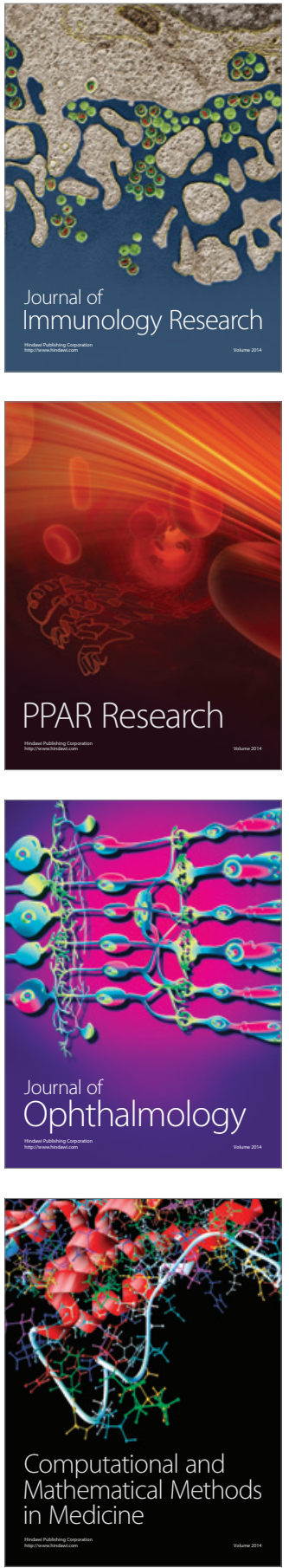

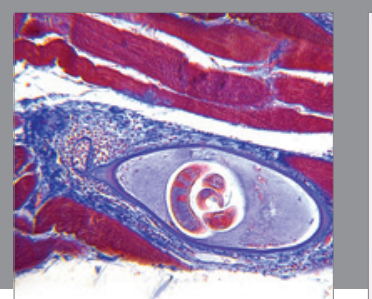

Gastroenterology Research and Practice

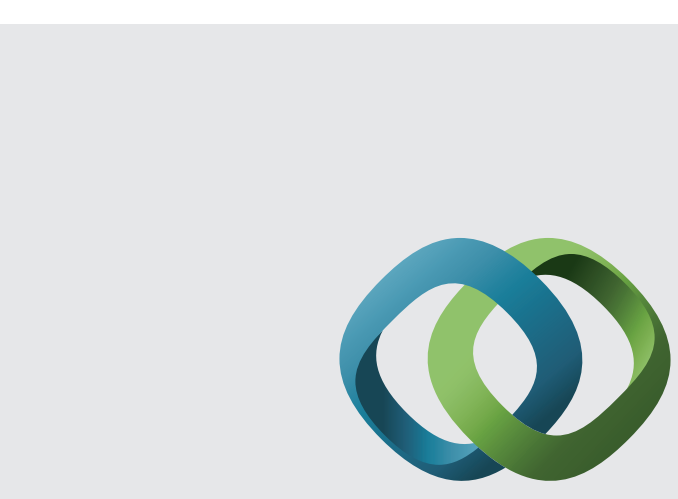

\section{Hindawi}

Submit your manuscripts at

http://www.hindawi.com
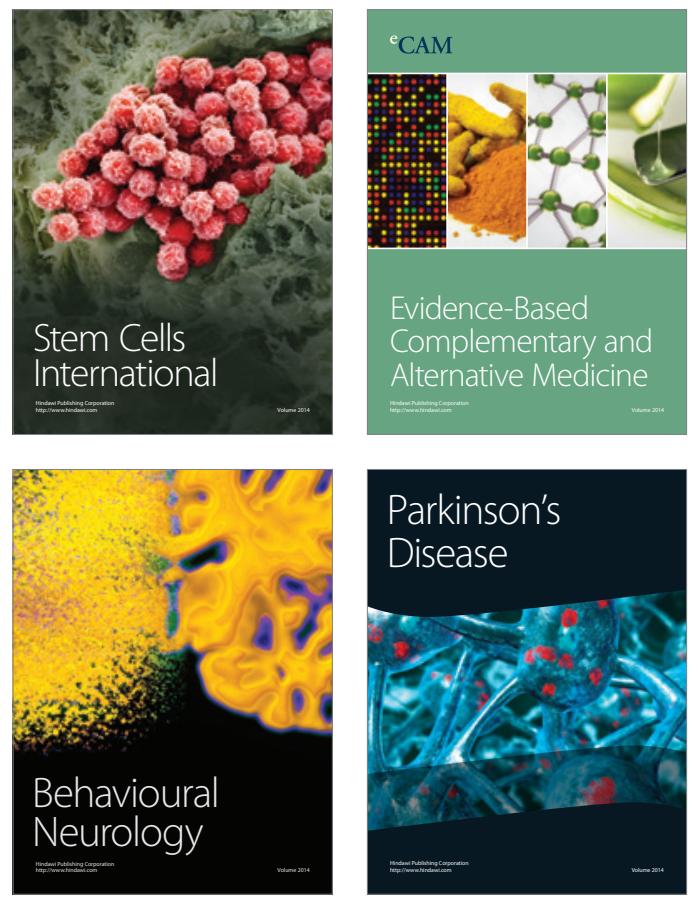
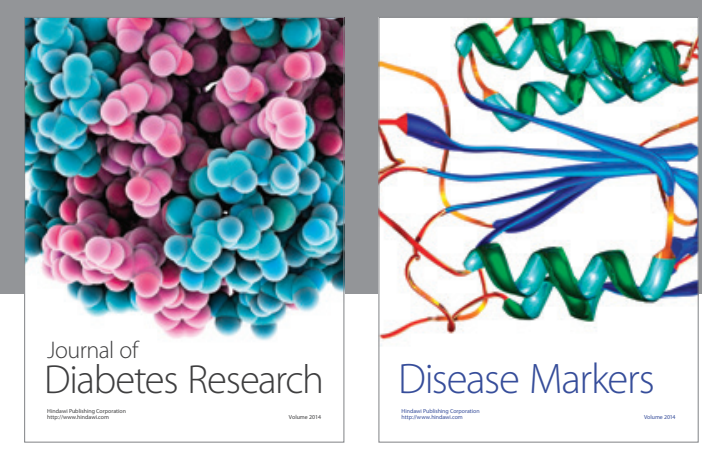

Disease Markers
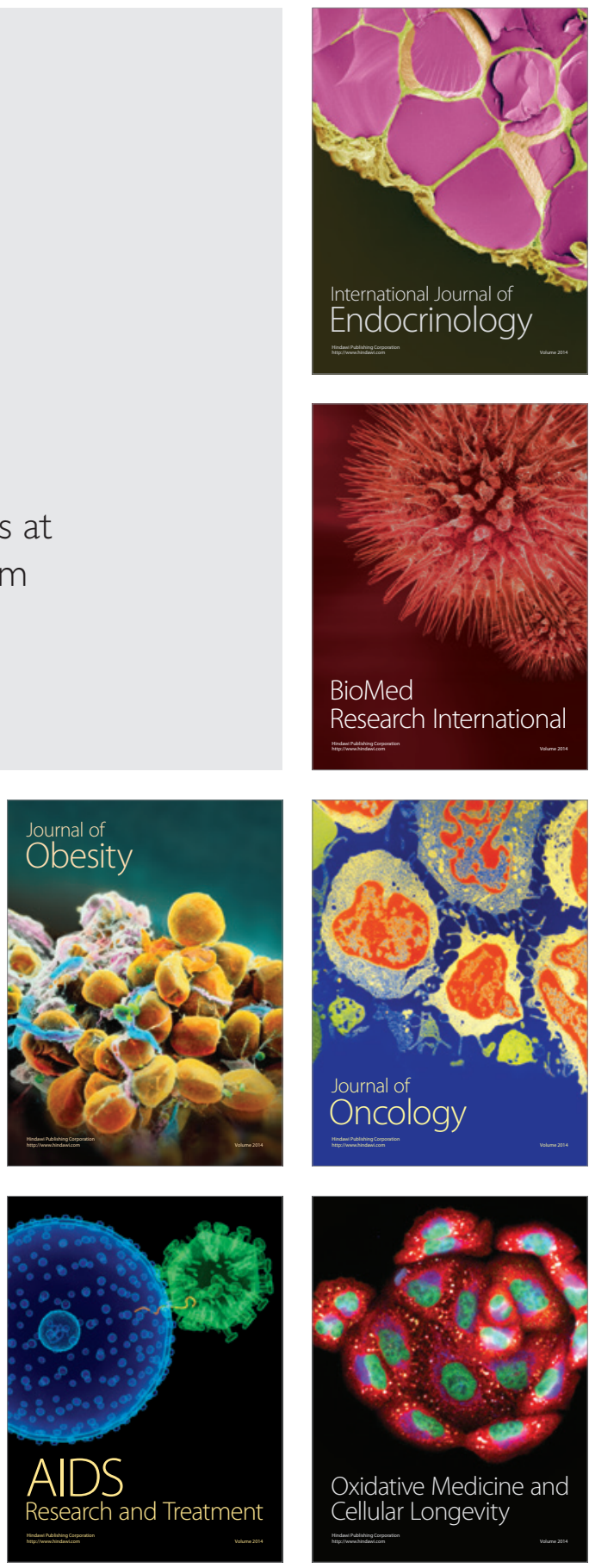